\title{
História, arte e política: o muralismo do boliviano Miguel Alandia Pantoja
}

\author{
Everaldo de Oliveira Andrade*
}

Resumo: Este artigo pretende avaliar em que medida arte e política se expressaram na criação e na ação do artista e militante político boliviano Miguel Alandia Pantoja, ativo participante de momentos centrais da História do seu país como a guerra do Chaco, a revolução de 1952 e a Comuna de La Paz de 1971. As influências do indigenismo andino e do muralismo mexicano parecem ter-se cruzado com as opções políticas de Alandia e com seu engajamento na proposta dos artistas ligados ao Manifesto por Uma Arte Revolucionária e Independente lançado por André Breton, Diego Rivera e Leon Trotski em 1936, permitindo o surgimento de uma obra original, polêmica e marcante para a História latino-americana.

Palavras-chave: muralismo latino-americano, indigenismo boliviano, arte e política

Este artigo pretende avaliar em que medida arte e política se expressaram na criação e na ação do artista e militante político boliviano Miguel Alandia Pantoja, ativo participante de momentos centrais da História do seu país como a guerra do Chaco (1932-1935), a revolução de 1952 e a Comuna de La Paz de 1971. As influências do indigenismo andino e do muralismo mexicano parecem ter-se cruzado com as opções políticas de Alandia e com seu engajamento na proposta dos artistas ligados ao Manifesto por Uma Arte Revolucionária e Independente lançado por André Breton, Diego Rivera e Leon Trotski em 1936, permitindo o surgimento de uma obra original, polêmica e marcante para a História latino-americana. Esta particularidade da trajetória pessoal de Alandia - que aliava arte e atividade política - refletiu-se com intensidade em sua produção artística e incorporou influências culturais diversas que devem ser recuperadas.

\section{Indigenismo andino e crítica social}

Miguel Alandia Pantoja, nascido em 27 de março de 1914 na zona mineira de Catavi próxima a Potosi, lutou jovem na guerra do Chaco (1932-1935) e foi prisioneiro dos paraguaios antes de voltar para casa. Seus primeiros trabalhos estão inflamados pelo tema da guerra e da exaltação indigenista. É um momento particular de afirmação de 
uma identidade nacional boliviana, de fratura profunda do poder oligárquico dos grandes mineradores de estanho e proprietários de terras com as maiorias nacionais no campo e nas cidades. O pós-guerra é marcado pela ascensão de novas forças políticas, organização de sindicatos operários nas minas de estanho e mobilizações indigenistas/camponesas mais freqüentes.

O indigenismo pôde ser visto durante muito tempo como parte de um movimento latino-americano de conteúdo nacionalista, antiimperialista e de crítica social, que se expressou inicialmente com grande intensidade na arena cultural. $O$ indigenismo associado à crítica social marcou as sociedades em que havia desagregação de valores culturais e sociais tradicionais das comunidades e lutas internas de caráter classista e étnico (Polar, 2000, p.194). Este movimento, por um lado, buscava raízes e identidade nas origens históricas da América Latina e, ao mesmo tempo, na modernização que se dava através de vínculos com as vanguardas artísticas nas primeiras décadas do século XX (ibidem, p.193). José Carlos Mariátegui assinalou ainda que era preciso realizar uma distinção entre o indianismo como produção cultural realizada pelos próprios índios através de seus códigos, do indigenismo como a vasta criatividade do lado ocidental das nações andinas buscando informar sobre o universo, e o homem indígena a partir de outras posições sociais e culturais e, nesta perspectiva, obra de mestiços no sentido histórico, social e cultural ${ }^{1}$. O indigenismo como movimento cultural, ao disseminar-se pelos países andinos de maiorias indígenas, foi um dos elos que atraiu a atenção de Miguel Alandia para as temáticas sociais. Ele sofreu claras influências do pintor indigenista boliviano Cecilio Guzman de Rojas, que era muito ligado ao indigenismo literário de Gamaliel Churata do grupo Orkopata ${ }^{2}$.

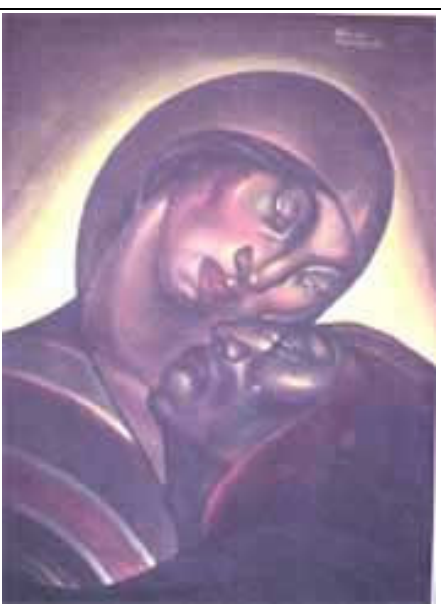

Figura 1 - A marca do indigenismo nas primeiras obras de Alandia. 
A presença de dois universos culturais diversos esteve sempre presente na literatura indigenista. O livro Aves sin nido, de Clorinda Matto de Turner, publicado no Peru em 1889, é considerado um marco ao desenvolver esta temática na literatura latino-americana. Contém um tom de denúncia da situação social e econômica do índio e busca representar a linguagem, a cultura e o modo de pensar dos indígenas. Na Bolívia as obras de Alcides Arguedas, em particular Wuata Wara, de 1904, e Raza de Bronze, de 1919, constituem-se em fontes importantes e iniciais desta mesma trajetória literária ${ }^{3}$. A obra Huasipungo, escrita em 1934 pelo equatoriano Jorge Icaza, busca a redefinição do nacional a partir de referenciais indígenas e de utopias andinas de restauração incaica. A denúncia de Icaza sobre a crua e brutal exploração sofrida pelos índios dos Andes nas grandes fazendas deixará marcas profundas no imaginário latino-americano, reafirmando-a como referencial para as obras de outros artistas envolvidos com a mesma temática.

A denúncia da exploração dos índios expressa no campo da cultura refletia, por outro lado, uma fermentação social profunda ao mesmo tempo em que ajudará a alimentar uma práxis em movimentos e lutas sociais com maior intensidade a partir da década de 1920. O indigenismo clássico com seu tom denunciador e reivindicativo deixou de prosperar na literatura após a década de 1940 com a mesma intensidade, sendo substituído por um neo-indigenismo com tom mais antropológico que social, diluindo o tom reivindicativo com a incorporação de novas técnicas narrativas. Como destacou Irlemar Chiampi, o indigenismo literário tão em voga nos anos 1920 e 1930, foi em grande parte superado após a $2^{\mathrm{a}}$ Guerra Mundial, tanto em sua versão utópica com fundamento na mestiçagem, como no utopismo com fundamento autócne que buscava resgatar os valores das sociedades indígenas reprimidas. Essa superação teria se dado em grande parte pela redução do particularismo europeu e pelo "fenômeno da mestiçagem enquanto padrão diferenciador [que] funciona como suporte da reivindicação de uma identidade para o homem latino-americano no contexto ocidental" (Chiampi, 1980, p.122). De fato, o ressurgimento do indigenismo nos Andes estará, no final da década de 1960, muito mais ligado a uma crise política dos nacionalismos. No entanto, na Bolívia as conseqüências da Guerra do Chaco terminada em 1935 e a Revolução de 1952 parecem ter destacado aspectos particulares no indigenismo local através de um renascimento de suas temáticas. A obra de Alandia representou parte 
deste ressurgimento indigenista, porém com uma crítica social que incorporava novas influências artísticas e políticas como veremos.

\section{$O$ contato com o muralismo mexicano}

No começo da década de 1940 Alandia adere ao trotskismo pelas mãos de seu amigo Guillermo Lora e reorienta seus trabalhos para a transformação social. Durante esse período sofre todos os reveses da esquerda boliviana, a repressão das ditaduras militares de E. Peñaranda, H. Hertzog e M. Urriolagoitia. Participa da constituição da federação dos mineiros e das atividades do seu partido político ${ }^{4}$. Conhece o exílio e as prisões e toma contato mais próximo com os debates e polêmicas entre os trotskistas e o mundo artístico. É nesse período que provavelmente se aproxima dos muralistas mexicanos, cujas obras forneceram a Alandia o fio condutor que lhe faltava para buscar fazer da arte um compromisso aberto com suas idéias políticas sem romper com o indigenismo de sua primeira fase artística.

As obras dos três grandes muralistas mexicanos José Clemente Orozco, Diego Rivera e David Siqueiros, pelo conteúdo engajado de suas abordagens, pelo resgate de temáticas indigenistas e populares, podem permitir uma aproximação e diálogo com as formas e temáticas do artista boliviano. Em particular o contato com Orozco e Rivera, que haviam se relacionado com Leon Trotski em sua estada no México, teve relevante importância na obra do boliviano.

A influência do muralismo mexicano foi destacada em toda a América Latina e devia muito ao vento inspirador pós-revolução de 1910-1920. A figura de José Vasconcelos, ministro da educação de Álvaro Obregón, ao instituir o "programa do mural" e permitir a liberdade de estilo e de temáticas aos artistas, certamente colaborou para intensificar um movimento que já desabrochava anos antes. Os muralistas em princípio exigiam a erradicação da arte burguesa e viam na tradição indígena um modelo de ideal socialista e popular. Havia um compromisso de realizar uma arte para o povo, como diz a Declaração dos Princípios Sociais, Políticos e Estéticos:

A arte do povo mexicano é a manifestação espiritual mais importante e vital do mundo de hoje e sua tradição indígena a melhor de todas. E ela é grande precisamente porque, sendo popular, é coletiva, e é por essa razão que nosso principal objetivo estético consiste em socializar as manifestações artísticas que contribuirão para o total desaparecimento do individualismo burguês. ${ }^{5}$ 
Diego Rivera buscou contrastar o mundo moderno industrial com uma crítica à exploração do trabalho, além do contraste entre o México urbano e o rural visto como vital e pitoresco e não como atraso. Após uma viagem a Moscou, incorpora temas da iconografia revolucionária russa como a estrela, a foice e o martelo. Suas imagens combinavam crítica social, fé no progresso e enaltecimento do índio. No seu indigenismo Rivera inspirou-se na "escrita boustrofédon” dos códices indígenas précolombianos para pintar “A História do México”. Segundo Dawn Ades, buscou pintar os índios em termos realmente indígenas, entendendo e usando criativamente as estruturas e iconografia pré-colombiana (Ades, idem, p.174).

José Clemente Orozco, por seu lado, desenvolveu uma crítica aos desvios da revolução e sua obra encontrou mais dificuldades para ser assimilada, em particular "La trindade revolucionária" e a "Trinchera", de 1926. Negava-se a pintar propaganda e via confusão folclorista nas pinturas nacionalistas de seus colegas. Orozco divergia de Rivera em relação à atitude que um e outro tinham sobre o papel da arte nacionalista, o indianismo e a interpretação da história mexicana e da própria revolução. Muito da primeira fase de suas obras pintadas na Escuela Nacional Preparatoria em 1924 foi seriamente danificado pelos estudantes conservadores, como o "Cristo destruindo sua cruz”, que depois seria repintado em 1943 como versão em óleo sobre tela. Em 1926 ele retoma seus trabalhos e são desta época: "O banquete dos ricos enquanto os trabalhadores se desentendem", "A trindade revolucionária“, "A greve", "A trincheira" e “A velha ordem”. Os trabalhos de Orozco possuem uma clara crítica aos erros da revolução mexicana, como disse: "uma pintura não deveria ser um comentário, mas a coisa em si; não uma reflexão, mas uma compreensão; não uma interpretação, mas a coisa a ser interpretada" (ibidem, p.160). Posições que enfrentaram a oposição de Siqueiros, alinhado aos cânones estalinistas do realismo socialista e à conseqüente submissão e dirigismo do artista pela política imposta por esta orientação. Os murais de Alandia refletem muito dos traços de David Siqueiros, embora não houvesse identidade política entre ambos. Este era membro do Partido Comunista Mexicano e chegou a dirigir um atentado contra Leon Trotski no México. De Orozco, Alandia absorveu principalmente o indigenismo pictórico (Lora, 1983, p.156).

Uma das maiores identidades de Alandia com Orozco e Rivera se devia à negação da instrumentalização da arte pela política, ao compromisso com a liberdade e a revolução socialista. Sente-se aqui a influência do célebre Manifesto por uma Arte 
Revolucionária e Independente de julho de 1938, assinado por André Breton, Diego Rivera e Leon Trotski. Ponto forte do contato entre a trajetória de Rivera e Alandia, o engajamento político e a visão emancipatória da arte estão presentes na trajetória dos dois artistas. O manifesto, ao mesmo tempo em que fazia a crítica da sociedade burguesa, investia contra todas as formas de dirigismo da produção artística e cultural e em particular o realismo socialista defendido pelos stalinistas. A liberdade de criação artística erige-se como expressão mais acabada do compromisso artístico com a revolução:

Se, para o desenvolvimento das forças produtivas materiais, cabe à revolução erigir um regime socialista de plano centralizado, para a criação intelectual ela deve, desde o começo, assegurar um regime anarquista de liberdade individual. Nenhuma autoridade, nenhuma coação, nem o menor traço de comando. ... Consideramos que a tarefa suprema da arte em nossa época é participar conscientemente e ativamente da preparação da revolução. No entanto, o artista só pode servir à luta emancipadora quando está compenetrado subjetivamente de seu conteúdo social e individual, quando faz passar por seus nervos o sentido e o drama desta luta e quando procura livremente dar uma encarnação artística a seu mundo interior. ${ }^{6}$

A obra de Alandia pode ser vista como uma das mais acabadas tentativas de desenvolver essas teses. A História boliviana deu-lhe oportunidades excepcionais para aplicá-la.

\section{Alandia e a Revolução de 1952}

A Revolução de 1952 é um divisor de águas na História contemporânea da Bolívia, e produziu profundas modificações políticas, econômicas e sociais no país andino, como também importantes iniciativas no campo da cultura.

Miguel Alandia empunha um fuzil com outros milhares de ativistas pelas ruas de La Paz nos combates entre 9 e 11 de abril de 1952. O exército é derrotado juntamente com o poder das oligarquias mineradoras e do campo por milícias populares. Como militante do POR (Partido Obrero Revolucionário) participa da fundação da COB (Central Obrera Boliviana), e torna-se responsável pela edição de seu primeiro jornal $E l$ Rebelión e depois será membro da comissão de organização do primeiro congresso da COB. Ao lado das medidas revolucionárias como a nacionalização das grandes minas de estanho, a reforma agrária e a instauração do voto universal impulsionadas pela 
revolução, ergueram-se murais e outras obras de arte no Museu Nacional da Revolução e em outros espaços culturais e políticos para celebrar os acontecimentos de 1952.

O novo governo dirigido pelo MNR (Movimiento Nacionalista Revolucionario), depois de derrotar a ala esquerda e socialista da revolução encabeçada pelos trotskistas do POR de Alandia, buscará consolidar sua imagem e sua visão nacionalista de revolução, marcada por tentativas de controle oficial sobre o mundo cultural ${ }^{7}$. Uma das iniciativas neste campo foi incentivar artistas dispostos a tematizar o nacionalismo a partir das imagens das comunidades indígenas milenares e camadas populares.

A revolução desencadeara um vigoroso envolvimento de uma nova geração de artistas com a política, realçando tendências culturais que já se desenvolviam no seio de uma juventude de intelectuais e artistas nacionais igualmente sufocados pela estreiteza de horizontes oferecidos pela oligarquia boliviana. Até então nenhuma temática de conteúdo social ou político havia mobilizado de forma tão marcante a cultura do país. A História foi alçada diretamente como espaço de criação da arte. Convencionou-se chamar os artistas envolvidos ou próximos deste projeto de "Geração de 1952", que em comum possuíam o propósito explícito de fazer de sua arte um veículo de intervenção na vida política. Porém, com expressão das próprias tensões da época, emergiram grupos distintos. Um deles em torno das idéias de Alandia, do poeta Jaime Saenz, do futuro roteirista e cineasta Oscar Soria, entre outros, que lançam a revista Hombre, em 1954, com o objetivo de realizar obras de apelo e mobilização revolucionária. Outro grupo de artistas preferiu se dedicar a temas e formas abstratos de artes plásticas, ficando distanciados de um compromisso social e militante. Outros artistas alinharam-se quase que incondicionalmente ao MNR e aos seus propósitos de tornar a produção cultural reflexo das orientações políticas de governo.

O talento de Alandia como pintor e sua expressão como militante político, em que pese as profundas divergências que separavam os trotskistas do POR dos nacionalistas do MNR, lhe garantem espaço como artista para registrar a mobilização vitoriosa. Paz Estenssoro, como primeiro presidente pós-revolução, convidara Alandia para pintar vários murais em prédios públicos para homenagear a Revolução.

Os murais de Miguel Alandia se multiplicaram pelos espaços públicos. No Palácio do governo pintou em 1953 o mural "Historia de la Mina" com 86 metros quadrados. No auditório principal do Hospital Obrero de La Paz está o mural "Historia de la medicina", elaborado em 50 metros quadrados no ano de 1956 e que reconhece o avanço da ciência e seu diálogo com os saberes indígenas locais no desenvolvimento da 
medicina. Na empresa estatal YPFB (Yacimientos Petrolíferos Fiscales de Bolívia) pinta em 1958 mais de 30 metros quadrados com o tema "El Petróleo em Bolívia". No Palácio Legislativo pinta "Historia do parlamento", em 1961, e no Ministério das Relações Exteriores, em 1962, pinta o mural "Hacia el Mar" com 36 metros quadrados. No entanto, foi no monumento museu da Revolução Nacional, erguido na Praça Gualberto Villarroel em La Paz, que Alandia pintou sua principal obra "La lucha del pueblo por su liberación, reforma educativa y voto universal", obra com 160 metros quadrados realizada em 1964. Este mural, apesar de sua beleza artística, não deixou de ser polêmico.

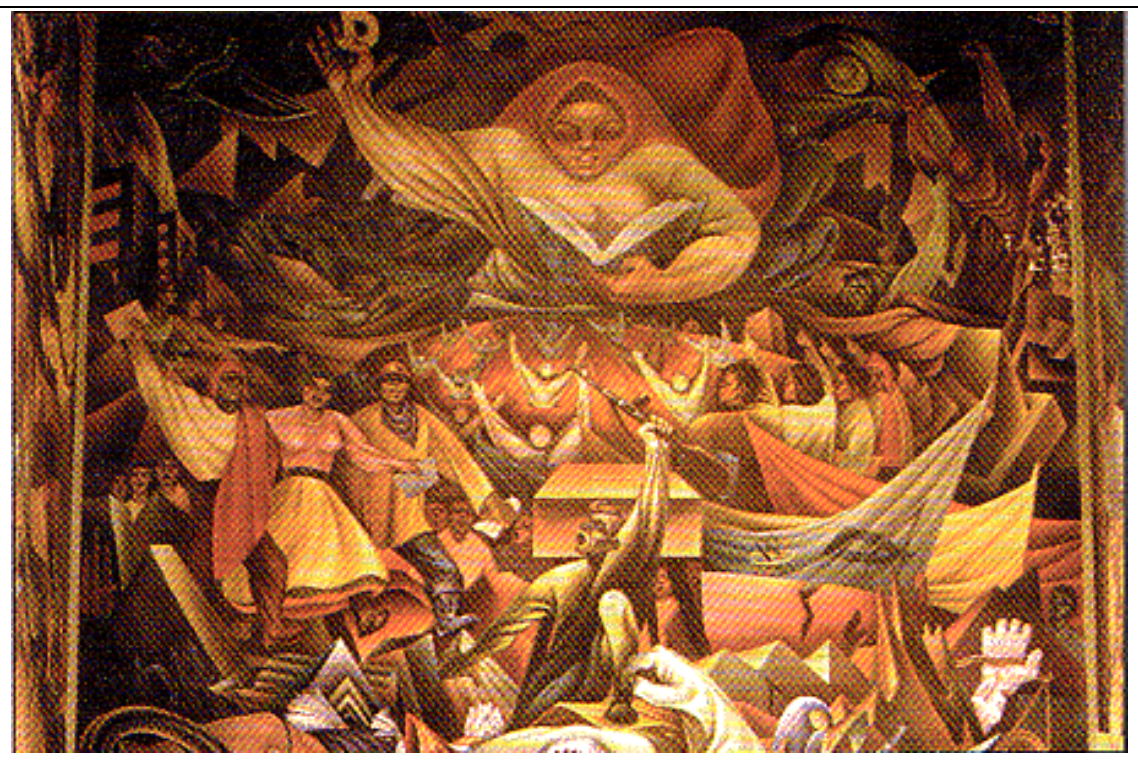

Figura 2 - Mural de Alandia no Museo de la Revolución em La Paz

Walter Sólon Romero, outro muralista talentoso, diretor nacional de artes plásticas na época e ligado ao MNR, fazia parte do grupo Anteo junto com o muralista Gil Imana. Ele entrou em choque com as concepções artísticas e culturais de Alandia no momento em que ambos iriam pintar os murais do Museu da Revolução. O muralista trotskista respondeu vigorosamente às críticas e escreveu artigos em que afirmava que Sólon pintara para a burguesia enquanto ele estava lutando nas ruas pela revolução. A disputa só foi resolvida por um inusitado sorteio em que os dois artistas dividiram em partes iguais a pintura do célebre mural. A polêmica em torno deste e de outros murais pintados por Alandia em prédios públicos e sindicatos foi intensa, refletindo tensões mais profundas sobre controle social do registro histórico da revolução através da arte. 
O contato de Diego Rivera com a obra de Alandia deu-se no momento inicial da revolução. Em maio de 1953 Diego Rivera, que participara do Congresso Continental de Cultura no Chile, chega à Bolívia para conhecer a revolução e seus protagonistas. Victor Paz Estenssoro se negou a recebê-lo, mas mesmo assim Rivera esteve no Palácio de Governo para ver o mural de Alandia. Entusiasmou-se particularmente com a qualidade plástica e o conteúdo progressista de suas obras, que revelavam não apenas a tradição nacional e pré-hispânica da Bolívia, mas a expressão de um movimento artístico coletivista no continente. Interessava ao grande muralista mexicano conhecer verdadeiramente o povo boliviano. Na Universidade San Andres Rivera participa no dia 20 de maio de uma conferência, além de numerosos encontros com militantes de esquerda boliviana e dos mineiros em Catavi. A amizade com Alandia permitiu que em 1957 o boliviano organizasse com o apoio de Rivera sua participação na Bienal de Arte do México, onde foi premiado.

Miguel Alandia tornou-se um dos principais expoentes desta vertente de artistas bolivianos dispostos a comprometer abertamente sua criação artística com a ação política revolucionária. Buscou sistematicamente disseminar suas obras pelos centros populares e organizações sindicais como uma forma de aproximar a mensagem política e artística dos setores sociais populares que buscava influenciar. Colaborou intensamente com os jornais partidários e de organizações sindicais com uma grande variedade de desenhos e gravuras centradas no tema da ação da classe operária. Via a pintura como parte de um amplo trabalho de agitação política, de forma que sua atividade como militante de grande talento confundiu-se constantemente com a do artista engajado e criativo.

\section{Alandia e a Comuna de La Paz (Assembléia Popular de 1971)}

Com o golpe militar do general René Barrientos em novembro de 1964, uma nova situação política abria-se na Bolívia. A mensagem política e revolucionária dos murais pintados por Alandia durante o período posterior a 1952 se tornou insuportável aos militares no poder. Muitas destas obras, que imortalizavam a ação dos mineiros, dos camponeses índios, do povo boliviano nos embates revolucionários de 1952 e dos anos seguintes, foram destruídas pelos governos militares que se sucederam após 1964. Os três grandes murais pintados em prédios do governo nacional somavam algo próximo de $206 \mathrm{~m}^{2}$ de cores populares, mineiros e camponeses em armas tomando as ruas do país. 
Era preciso rasgar da memória da revolução e de seus protagonistas vitoriosos quase imortalizados nos murais de Alandia. Várias obras foram destruídas ao longo de maio de 1965 por golpes de picaretas ou tinta com a mesma violência com que se eliminaram centenas de dirigentes políticos dos sindicatos e partidos opositores à ditadura ${ }^{8}$.

O movimento sindical reagiu à destruição das obras de Alandia. Um dos exemplos marcantes da relação próxima entre o mundo artístico e o movimento operário foi demonstrado pelo posicionamento da Federação dos Mineiros em seu jornal diante do vandalismo do governo:

É um dever revolucionário defender a obra de arte, por cima de toda consideração ideológica ou estética. É inconcebível que se peça que os murais de Alandia sejam recobertos com pintura branca .... Se se chegar ao extremo ingrato de se decidir pela destruição dos murais de Alandia, a FSTMB está disposta a transladá-los à sua sede social antes que permitir semelhante ato de vandalismo. $^{9}$

Com o fim do governo Barrientos em 1969, ascende ao poder o general Ovando Candía. As tensões políticas internas entre setores militares obrigam o regime a flexibilizar e conceder limitadas medidas democráticas, que são rapidamente aproveitadas pela COB e partidos de oposição para se rearticularem. A COB realiza seu $4^{\circ}$ congresso em maio de 1970 e propõe a organização de uma frente antiimperialista contra os militares. A situação política do país avança para um tensionamento político crescente.

Alandia está envolvido nesse período com a rearticulação do sindicato dos artistas e as atividades do seu partido político. Uma de suas obras mais marcantes da época é um quadro que retrata o assassinato dos líderes mineiros do POR Isaac Camacho e César Lora. Cores fortes e grandes traços expressam a dor e a revolta pela perda de camaradas de luta política apaixonada. Vive-se um sentimento geral de retomada do ardor revolucionário de 1952 que em breve desabrochará. 


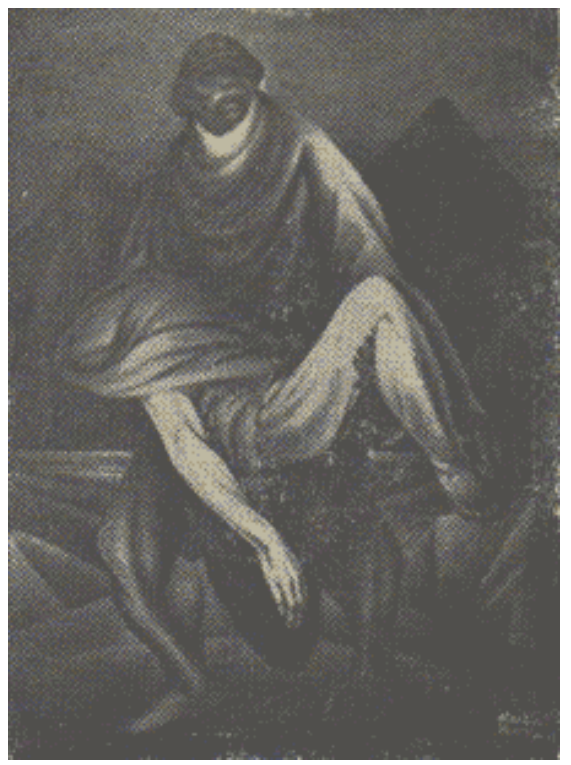

Figura 3 - Alandia homenageia os líderes mineiros assassinados, Isaac Camacho e César Lora

Os setores militares mais retrógrados exigem uma reação do general Ovando para conter a abertura democrática. Há divisões crescentes entre os militares e em outubro de 1970 a Bolívia é convulsionada por uma série de golpes de estado. Uma situação inusitada de divisão no seio do exército com seis generais reivindicando a presidência do país em apenas um dia. Esta conjuntura particular só terminou provisoriamente com a aceitação do general nacionalista Juan José Torres à presidência no dia 8 de outubro, que, apoiado por uma greve geral decretada pela $\mathrm{COB}$, faz recuar os militares reacionários ligados ao general Rogelio Miranda e ao coronel Hugo Banzer.

No interior da central sindical organiza-se um Comando Político que, após impulsionar a greve geral, negocia a formação de um governo comum com Torres. A COB oferece ministros, mas ao final o general nacionalista recusa um acordo que fragilizaria ainda mais seu governo. Neste momento surge e é aprovada no interior da COB uma proposta dos trotskistas do POR de se constituir um órgão de poder próprio e independente do governo Torres - um parlamento operário popular -, iniciativa conhecida como Assembléia Popular ou Comuna de La Paz. A memória de 1952 ressurgia com toda a intensidade. A idéia de que uma nova ruptura revolucionária se precipitava tomou conta dos setores mais politizados do movimento sindical e das 
organizações políticas de esquerda. A direita militar se rearticula e fracassa uma nova tentativa golpista em 10 de janeiro de 1971. O governo Torres estava sob o fogo cruzado dos militares golpistas e da Assembléia Popular (Andrade, 2002).

Miguel Alandia estava novamente no centro dos acontecimentos políticos decisivos de seu país em 1971. Participara do $4^{\circ}$ congresso da COB em maio de 1970 como delegado do sindicato dos artistas e atuara nas jornadas de outubro como militante do POR. Posteriormente, nos meses que antecedem a abertura da Assembléia Popular em junho de 1971, participa novamente como delegado do sindicato dos artistas revolucionários. Na Assembléia Popular Miguel Alandia dirige a Comissão de Defesa e Milícias, encarregada de armar os sindicatos e militantes em milícias populares para fazer frente ao exército.

Em fevereiro de 1971 Alandia realiza uma importante exposição em La Paz e que também será sua última em solo boliviano. Uma rara entrevista da época reafirmava os compromissos de sua arte:

La pintura mural creo que es la pintura del porvenir, no sólo por ser monumental y expresar las esperanzas de las grandes y anchas masas, sino también porque la transformación de la sociedad impone que al expresarse de forma monumental, la plástica exprese el sentimiento democrático y humano de la sociedad en su conjunto, es decir, que la pintura mural debe sustituir en el futuro a los pequeños museos en que hoy se conservan las obras maestras del pasado. Mi mayor anhelo es siempre pintar murales, lo que no me impide hacer pintura de caballete. ${ }^{10}$

Alandia não representava apenas seu partido político, embora o trotskismo houvesse exercido importante atração sobre toda uma geração de artistas e sua adesão determinada à militância revolucionária não deveria ser vista apenas como um ato isolado e individual. Como o cineasta Jorge Sanjinés e o grupo Ukamau também demonstravam, havia um compromisso político comum de um grupo mais amplo de artistas aos ideais revolucionários do socialismo e da revolução que davam passos para ocupar com maior intensidade a cena cultural entre 1970 e 1971.

Os debates da Assembléia Popular, tomados por ásperos confrontos políticos e ideológicos, nem por isso deixaram de refletir a presença marcante dos artistas revolucionários. Um movimento cultural e artístico estava em desenvolvimento com a Assembléia Popular de 1971, galvanizado pelo tensionamento político e social do momento. Uma Resolução de 2 de julho de 1971 exigia a proteção e preservação das obras dos artistas revolucionários do país, colocando-se a favor da preservação da 
"cultura e da arte revolucionária". Este posicionamento era revelador não apenas do amplo leque de preocupações que tomava conta dos seus delegados, mas também refletia a participação política engajada, ainda que limitada, de setores do mundo artístico e cultural no processo de constituição da Assembléia Popular (Resolución, 1971). Respirava-se uma vitalidade criativa, política e cultural que possuía expressão na própria constituição da Assembléia Popular como possibilidade histórica de um novo poder revolucionário. Por isso, esse momento iluminou por um breve tempo a cena histórica, interrompendo como um hiato, duas longas extensões do militarismo na Bolívia.

\section{Conclusões}

A atividade de Miguel Alandia não deixou de ser criticada por adversários políticos e mesmo por seus camaradas mais próximos, que destacaram certo voluntarismo e superficialidade estética de seus trabalhos. Sua obra de muralista principalmente sobreviveu às polêmicas e ataques como registro poderoso da história do movimento operário e popular de 1952 e 1971. Como homem de ação e militante revolucionário, registrou igualmente com traços fortes e profundos o seu lugar na história boliviana. Chegou a pintar cerca de 562 metros quadrados de murais em 16 grandes obras que combinam série e jogos, além de centenas de telas e caricaturas publicadas em jornais partidários e sindicais. Uma intervenção da Unesco em 1980 conseguiu salvar alguns murais da sanha destruidora da ditadura Garcia Meza. Mais recentemente (2002) cinco de seus murais com quase 64 metros quadrados de pintura e sediados num órgão público de La Paz começaram a ser restaurados. Em 2003 o Museo de la Revolución em La Paz foi reaberto e muitos dos trabalhos de Alandia vieram novamente a público. Alandia morreu em 2 de outubro de 1975, aos 61 anos, no exílio no Peru, após fugir do golpe sangrento de Hugo Banzer contra a Assembléia Popular em agosto de 1971.

Em Miguel Alandia ação e militância política e cultural confundiram-se numa relação nem sempre coerente e sem tensões, como não poderia deixar de ser na intenção do artista confrontado com a realidade. Não buscou apenas refletir de forma artística e pela imagem a história, mas fazer da arte um instrumento ativo de ação revolucionária sobre a história. As rupturas históricas e sociais autênticas fazem tremer todos os pilares da vida social e a produção cultural não permanece incólume a estes abalos sísmicos da 
história. Pelo contrário, como expressão das mais sensíveis da sensibilidade humana, a cultura artística registra sob sua linguagem e cores particulares o movimento real das grandes massas humanas. A força da arte como interpretação e ação histórica, particularmente a visão revolucionária, socialista e radical de Alandia, pagou um preço alto por sua autonomia, ousadia e independência. Mas o impacto político e cultural de suas obras revelaram a eficácia de suas ações e a permeabilidade densa da cultura pela política e pela história.

\section{REFERÊNCIAS BIBLIOGRÁFICAS}

ADES, Dawn. Arte na América Latina. São Paulo: Cosac \& Naify, 1997.

ANDRADE, Everaldo de Oliveira. A Comuna de La Paz - História da Assembléia Popular de 1971. São Paulo, 2002. Tese (Doutorado em Historia) - FFLCH - USP.

As revoluções na Bolívia. São Paulo: Unesp, 2007 (no prelo).

CHIAMPI, Irlemar. O Realismo maravilhoso. São Paulo: Perspectiva, 1980.

FACIOLI, Valentim (Org.). Breton-Trotski, por uma arte revolucionária independente.

Rio de Janeiro: Paz e Terra, 1985.

LORA, Guillermo. Historia Del POR. La Paz: Isla ,1978.

Figuras del trotskismo boliviano. La Paz: Masas, 1983.

MARIÁTEGUI, José Carlos. Sete ensaios de interpretação da realidade peruana. São Paulo: Alfa-Ômega, 1975.

MITRE, Antonio. O Dilema do centauro: ensaios de teoria da história e pensamento latino-americano. Belo Horizonte: Editora da UFMG, 2003.

POLAR, Antônio Cornejo. O condor voa: literatura e cultura latino-americanas. Belo Horizonte: Editora da UFMG, 2000.

RESOLUCIÓN de la Asamblea Popular. La Paz, 2 de julho de 1971.

SCHWARTZ, Jorge. Vanguardas latino-americanas. São Paulo: Edusp-Iluminuras, 1995.

ANDRADE, Everaldo de Oliveira. History, art and politics: the muralism of the Bolivian Miguel Alandia Pantoja. História, São Paulo, v. 25, n. 2, 147-161, 2006.

Abstract: This article intends to evaluate how art and politics are expressed both in the creation and in the action of the Bolivian militant politician Miguel 
Alandia Pantoja, who was an active participant in decisive moments of his country's history, as the Chaco War, the 1952 Revolution and the Commune of La Paz in 1971. The Andean indigenismo and the Mexican muralist influences seemed to have crossed with Alandia political options and with his enrollment at the proposal made by artists related to the Manifesto for a Revolutionary and Independent Art launched by Andre Breton, Diego Rivera and Leon Trotski in 1936, allowing the uprising of an original and controversial artistic creation for Latin American history.

Keywords: Latin American muralist, Bolivian indigenism, art and politics.

Artigo recebido em 8/2006. Aprovado em 11/2006.

\section{NOTAS}

\footnotetext{
* Professor do Curso de História, Universidade Guarulhos (UnG). Guarulhos - SP - Brasil
}

${ }^{1}$ Não há evidências de que tenha havido algum contato e envolvimento intenso de Alandia com a obra de Mariátegui para sua posterior orientação política socialista. O marxista peruano José Carlos Mariátegui valorizou a tradição indígena e a permanência das comunidades como marcos de sobrevivência ancestral que deveria integrar-se ao futuro mundo socialista. Sua contribuição central, em grande medida relegada pela esquerda marxista latino-americana, foi não desprezar o passado de lutas indígenas, mas associá-lo à resistência dos índios andinos, seu apego comunitário à terra com a luta pela sociedade socialista. Via o índio incorporado ao projeto socialista a partir da combinação de particularidades locais à luta mais ampla contra o capitalismo (ver Mariátegui, 1975).

${ }^{2} \mathrm{Na}$ poesia do grupo Orkopata na cidade de Puno - Peru, o vanguardismo literário indigenista expressouse com maior reconhecimento e intensidade. Seu principal animador foi Gamaliel Churata, que permaneceu longo tempo na Bolívia e em contato com os artistas deste país. A obra de Miguel Alandia provavelmente tenha sido uma ponte entre o indigenismo andino e o vanguardismo, entre o nacional/indígena e o universal, características que estarão também presentes no muralismo mexicano (ver Schwartz, 1995).

${ }^{3}$ Antônio Mitre destacou em seu ensaio sobre a obra de Alcides Arguedas a estreita relação que o autor estabeleceu entre o problema étnico e a estrutura do poder despótico, temas que posteriormente foram relegados a um plano menor pela revolução de 1952 ao abordar a questão indígena/camponesa. A obra de Alandia, no entanto, retomara o indigenismo sob uma ótica radical (ver Mitre, 2003).

4 Os trotskistas bolivianos organizavam-se no POR desde 1935 e lograram grande influência política entre os trabalhadores mineiros. A força dos mineiros decorria do lugar central da produção do estanho na economia do país. Em 1943 os mineiros com impulso do POR fundam uma federação sindical, que se torna uma poderosa força política de resistência aos governos militares da época entre até 1952 . Foi em grande parte pela influência do POR entre os mineiros que se formou a $\mathrm{COB}$ e as minas foram nacionalizadas (ver Andrade, 2007 - no prelo)

${ }^{5}$ El Machete, cidade do México, 1923. Citado em Ades, 1997.

6 "Manifesto Por uma arte revolucionária independente", México, 25 de julho de 1938. Publicado em Facioli, 1985.

${ }^{7}$ O MNR, liderado pelo advogado Victor Paz Estenssoro, vencera as eleições de 1951 respaldado por uma ampla mobilização de massas. Porém as eleições foram anuladas por um golpe militar. Quando o partido tenta tomar o poder através de uma conspiração em 9 de abril de 1952, desencadeia-se uma revolução de massas, radical e influenciada por muitas das propostas dos trotskistas do POR. Milícias populares armadas e a organização de uma representativa central sindical, a COB (Central Obrera Boliviana), exigem a nacionalização das grandes minas, o início da reforma agrária e o fim do exército. Por volta de 1953 o MNR, com a ajuda dos EUA, consegue conter a radicalização da revolução, rearticular o exército e afastar os trotskistas do controle da COB (ver Andrade, 2007 - no prelo)

${ }^{8}$ Jornal Los Tiempos, Cochabamba, 5 de setembro de 2004.

9 "La FSTMB sale en defensa del arte revolucionario", citado por Lora,1978, p.393-4.

${ }^{10}$ El Diário, 24 de janeiro de 1971. 